\title{
Acylated Flavonol Glycosides and Terpenoids from the Leaves of
}

\section{Alibertia sessilis}

\author{
Roberto S. Gallegos Olea ${ }^{a}$, Nídia F. Roque ${ }^{a}$, and Vanderlan da S. Bolzani ${ }^{b}$ \\ ${ }^{a}$ Instituto de Química, Universidade de São Paulo, CP 26077, 05599-970 - SP, Brazil \\ ${ }^{b}$ Instituto de Química, UNESP, SP, Brazil
}

Received: June 17, 1996

\begin{abstract}
Dois novos flavonóis glicosilados, juntamente com iridóides, triterpenóides, esteróides e tocoferolquinona, foram isolados das folhas de Alibertia sessilis (Rubiaceae). As estruturas dos flavonóides foram determinadas através de métodos espectroscópicos, principalmente da $\mathrm{RMN}$ de ${ }^{13} \mathrm{C}$ e de ${ }^{1} \mathrm{H}$.

Two novel acylated flavonol glycosides, along with iridoids, triterpenes, steroids and $\alpha$-tocopherolquinone, were isolated from the leaves of Alibertia sessilis (Rubiaceae). The determination of the structures of the new compounds was based mainly on ${ }^{1} \mathrm{H}$ - and ${ }^{13} \mathrm{C}-\mathrm{NMR}$.
\end{abstract}

Keywords: Alibertia sessilis, Rubiaceae, acylated flavonol glycosides, iridoids, terpenoids, $\alpha$-tocopherolquinone

\section{Introduction}

In the course of our continuing search for new active antifungal compounds from Alibertia (Rubiaceae) found in "Cerrado" region of S. Paulo, we studied Alibertia sessilis (Vell.) K. Schum. collected in Itirapina, in the state of São Paulo, Brazil. Previous investigations of the leaves of $A$. macrophylla resulted in the isolation of fungitoxic non-glycosidic iridoids $1 \beta$ and $1 \alpha$-hydroxydihydrocornin aglycones, and the caffeic acid esters: 2-phenylethyl caffeoate and 2-methyl-4-hydroxybutyl caffeoate ${ }^{1}$. A. edulis, an other species collected in the same region, was also investigated, and no active compound was detected ${ }^{2}$. Relatively few chemical studies of the Alibertia genus have been reported, despite evidence of its rich terpenoidic constitution ${ }^{3}$.

In the present study, from the leaves of A. sessilis we obtained large amounts of the triterpenes oleanolic, ursolic, and epi-betulinic acid, and small amounts of the iridoids gardenoside, deacetylasperuloside, and 10-dehydrogardenoside, together with the fungitoxic $\alpha$ - and $\beta$-gardiol. Besides iridoids and triterpenes, the flavonols quercetin-3-Orutinoside, quercetin-3-O- $\beta$-D-(2"-O-trans- $p$-coumaroyl) -rutinoside (1) and kaempferol-3-O- $\beta$-D-(2"-O-trans$p$-coumaroyl)-rutinoside (2) were isolated. These last two

Present address: Departamento de Química, UFMa. glycosides are being reported for the first time from a natural source.

\section{Results and Discussion}

The hexanic extract of the leaves of Alibertia sessilis was submitted to a chromatographic process to afforded sitosterol and $\alpha$-tocopherolquinone, identified by comparison with authentic samples. After methylation, the $\mathrm{CH}_{2} \mathrm{Cl}_{2}$ extract of the leaves gave ursolic, oleanolic, and epi-betulinic acid methyl esters $^{2,4}$. After chromatographic separations, the butanolic soluble part of the hydroalcoholic extract afforded a mixture of the isomeric iridoids $\alpha$ and $\beta$ gardiol $^{5}$, in addition to gardenoside and deacetylasperulosidic acid methyl ester ${ }^{6,7}$. These compounds were identified by comparing the spectroscopic data with the literature ${ }^{5-7}$.

Gel permeation chromatography of the EtOAc soluble part of the hydroalcoholic extract gave quercetin3-O-rutinoside ${ }^{8}$ (rutin) and a mixture of the new acylflavonol glycosides 1 and 2 . These were purified by subsequent preparative TLC. The ${ }^{1} \mathrm{H}-\mathrm{NMR}$ of 1 and 2 showed signals that suggested the structure of quercetin and kaempferol, respectively, for the aglycones of the compounds. In both spectra signals corresponding to the trans $p$-coumaroyl group and a rhamnose sugar portion were also found (Table 1). The anomeric proton of the rhamnose ap- 
Table 1. ${ }^{1} \mathrm{H}-\mathrm{NMR}$ spectral data for compounds 1 and 2 in DMSO-d 6 *

\begin{tabular}{|c|c|c|}
\hline $\mathbf{H}$ & 1 & 2 \\
\hline 6 & $6.14, \mathrm{~d}(1.8)$ & $5.90, \mathrm{~d}(1.8)$ \\
\hline 8 & $6.33, \mathrm{~d}(1.8)$ & $6.07, \mathrm{~d}(1.8)$ \\
\hline $2^{\prime}$ & $7.48, \mathrm{~d}(1.8)$ & $7.88, \mathrm{~d}(8.8)$ \\
\hline $3^{\prime}$ & & $6.84, \mathrm{~d}(8.8)$ \\
\hline 5 & $6.83, \mathrm{~d}(9.0)$ & $6.84, \mathrm{~d}(8.8)$ \\
\hline $6^{\prime}$ & 7.51, dd (9.0 and 1.8) & $7.88, \mathrm{~d}(8.8)$ \\
\hline $1 "$ & $5.56, \mathrm{~d}(8.4)$ & $5.54, \mathrm{~d}(8.3)$ \\
\hline $2 "$ & $4.87, \mathrm{t}(8.4)$ & $4.80, \mathrm{t}(8.3)$ \\
\hline $3 "$ & ca 3.5 & ca 3.5 \\
\hline $4 "$ & ca 3.4 & ca 3.3 \\
\hline $5 "$ & ca 3.4 & ca 3.3 \\
\hline $6 "$ & ca 3.7 & ca 3.7 \\
\hline 1, & $4.36, \mathrm{~s}$ & $4.35, \mathrm{~s}$ \\
\hline $2^{\prime,}$ & ca 3.4 & ca 3.2 \\
\hline 3, & ca 3.5 & ca 3.5 \\
\hline 4, & ca 3.1 & ca 3.1 \\
\hline 5, & ca 3.3 & ca 3.3 \\
\hline 6, & $0.98, \mathrm{~d}(6.0)$ & $0.99, \mathrm{~d}(6.0)$ \\
\hline $2, \cdot, \cdot, 6, \cdot$, & $7.52, \mathrm{~d}(8.0)$ & $7.51, \mathrm{~d}(8.5)$ \\
\hline $3,,,, 5,,$, & $6.78, \mathrm{~d}(8.0)$ & $6.77, \mathrm{~d}(8.5)$ \\
\hline $7^{\prime,,}$ & 7.56, d (15.6) & $7.58, \mathrm{~d}(15.6)$ \\
\hline $8,,$, & $6.37, \mathrm{~d}(15.6)$ & $6.36, \mathrm{~d}(15.6)$ \\
\hline
\end{tabular}

peared as a singlet $(\delta 4.36)$ in accordance with the $\alpha$ configuration. Another signal, which could be assigned to an anomeric proton of another sugar appeared at $\delta \sim 5.5(\mathrm{~d}, \mathrm{~J}=$ $8 \mathrm{~Hz}$ ) in both spectra.

The ${ }^{13} \mathrm{C}-\mathrm{NMR}$ spectra (Table 2 ) confirmed the structure of quercetin and kaempferol aglycones to $\mathbf{1}$ and $\mathbf{2}$, respectively. The presence of rhamnose and coumaroyl moieties was also confirmed. The localization of the carbohydrates in the flavonols at $\mathrm{C}-3$ was deduced by the chemical shifts of C-3, C-2, and C-4, the first being shielded and the latter two deshielded in relation to the free aglycones ${ }^{8}$. The rhamnose signals are unchanged, so the acyl group should be located on the other sugar moiety. The methylenic carbon of that sugar is deshielded by $6 \mathrm{ppm}$ when compared with that of glucose. A COSY ${ }^{1} \mathrm{H}^{-1} \mathrm{H}$ spectrum of 1 showed correlations between the anomeric proton signal at $\delta 5.56$ and a signal at $\delta 4.87(\mathrm{t}, \mathrm{J}=8.4 \mathrm{~Hz})$. These values suggested an acylation of the hydroxyl at $\mathrm{C}-2$ and a diaxial hydrogen coupling between $\mathrm{H}-2 / \mathrm{H}-1$ and $\mathrm{H}-2 / \mathrm{H}-3$. These data are in agreement with an acylated $\mathrm{C}-2$ glucose.

Comparative analyses of the ${ }^{13} \mathrm{C}-\mathrm{NMR}$ carbohydrate data of $\mathbf{1}$ and $\mathbf{2}$ with those of the glucose in rutin ${ }^{8,9,10}$ revealed that the
Table 2. ${ }^{13} \mathrm{C}-\mathrm{NMR}$ spectral data for compounds 1 and 2 in DMSO- $\mathrm{d}_{6}$.

\begin{tabular}{|c|c|c|}
\hline $\mathbf{C}$ & 1 & 2 \\
\hline 2 & 156.6 & 157.4 \\
\hline 3 & 133.0 & 132.6 \\
\hline 4 & 177.2 & 176.4 \\
\hline 5 & 161.4 & 161.4 \\
\hline 6 & 98.9 & 101.2 \\
\hline 7 & 164.7 & 166.4 \\
\hline 8 & 93.9 & 95.2 \\
\hline 9 & 156.9 & 156.1 \\
\hline 10 & 104.1 & 102.1 \\
\hline 1 ' & 121.2 & 121.3 \\
\hline $2^{\prime}$ & 116.4 & 130.9 \\
\hline $3^{\prime}$ & 145.0 & 115.7 \\
\hline $4^{\prime}$ & 148.8 & 160.4 \\
\hline 5 & 115.5 & 115.7 \\
\hline $6^{\prime}$ & 122.0 & 130.9 \\
\hline $1 "$ & 98.9 & 99.2 \\
\hline $2 "$ & 74.2 & 74.4 \\
\hline $3 "$ & 74.1 & 74.4 \\
\hline $4 "$ & 70.8 & 71.0 \\
\hline $5 "$ & 76.2 & 76.1 \\
\hline $6 "$ & 67.4 & 67.3 \\
\hline $1,$, & 101.1 & 101.3 \\
\hline $2^{\prime \prime}$ & 70.8 & 70.8 \\
\hline $3^{\prime \prime}$, & 70.6 & 70.8 \\
\hline $4^{\prime,}$, & 72.0 & 72.2 \\
\hline $5^{\prime,}$ & 68.6 & 68.8 \\
\hline $6^{\prime \prime}$, & 18.0 & 18.2 \\
\hline $1,,$, & 125.4 & 125.4 \\
\hline $2, \cdot,, 6, \cdot$, & 130.5 & 130.7 \\
\hline $3,,,, 5, \cdot$, & 116.0 & 116.4 \\
\hline $4,,$, & 160.0 & 160.6 \\
\hline $7,,$, & 145.1 & 146.3 \\
\hline $8,,$, & 114.6 & 114.6 \\
\hline $9,,$, & 166.0 & 168.2 \\
\hline
\end{tabular}

$\mathrm{C}-2$ of the glucose in $\mathbf{1}$ and $\mathbf{2}$ was deshielded by $+2 \mathrm{ppm}$, and that C-1 and C-3 are shielded by -2 ppm. These observations are in agreement with the location of the coumaroyl group at C-2 of the glucose moiety. Thus, the structures of the two new acylated flavonol glycoside isolated from Alibertia sessilis were established as quercetin-3-O- $\beta$-D-(2"-O-trans- $p$-coumaroyl) -rutinoside (1) and kaempherol-3-O- $\beta$-D-(2"-O-trans-pcoumaroyl)-rutinoside (2). 


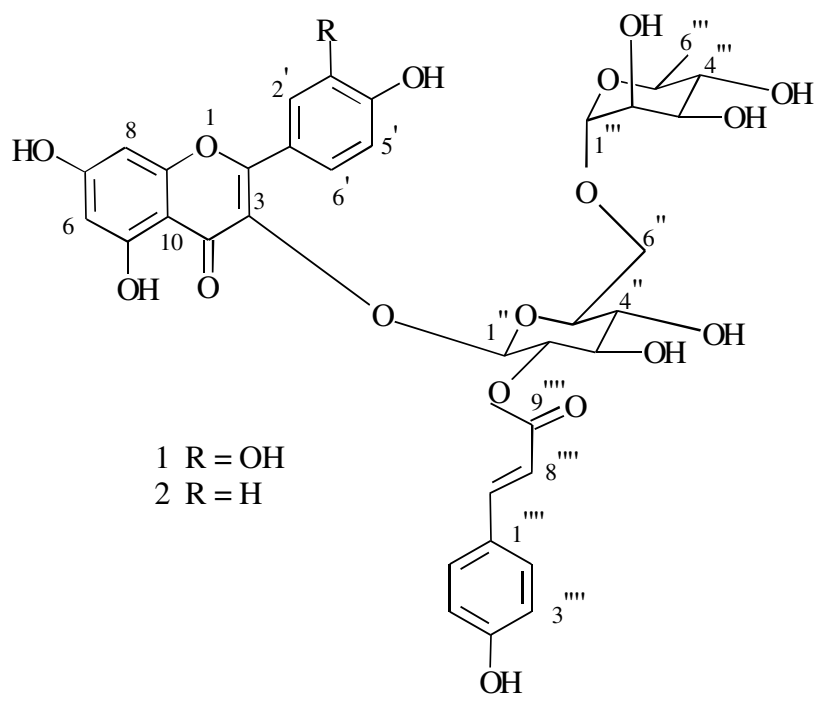

Scheme 1.

The occurrence of iridoids and triterpenes in Alibertia is in agreement with chemosystematic correlations and botanical positioning of this genus in Gardenieae ${ }^{3}$. However, the isolation of this type of flavonol is unusual if we consider the chemical composition of other Alibertia already described in the literature.

\section{Experimental}

\section{General experimental procedures}

NMR spectra were measured at $200 \mathrm{MHz}$ for ${ }^{1} \mathrm{H}$, with TMS as the internal standard and $50 \mathrm{MHz}$ for ${ }^{13} \mathrm{C}$, using the solvent signal as reference.

\section{Plant material}

Alibertia sessilis (Vell.) K. Shum. (Rubiaceae) was collected in the Itirapina Botanic Reserve, in the Cerrado region of São Paulo, Brazil. A voucher specimen is deposited at the Botanical Institute of São Paulo (number S.P. 110683).

\section{Extraction and isolation of the constituents}

Dried and powdered leaves (515 g) of A. Sessilis were successively extracted with hexane, methylene chloride and ethanol/water (6:4). The crude hexane extract (10.4 g) was fractionated on silica gel column chromatography. Further purification of the fractions by preparative TLC, eluted with $\mathrm{C}_{6} \mathrm{H}_{6}$ :EtOAc (9:1) yielded sitosterol (86 mg), $\alpha$-tocopherolquinone (29 mg), and fatty material.

The $\mathrm{CHCl}_{3}$ insoluble fraction $(1.2 \mathrm{~g})$ of the crude dichloromethanic extract $(9.5 \mathrm{~g})$ was methylated with $\mathrm{CH}_{2} \mathrm{~N}_{2}$. Preparative TLC eluted with $\mathrm{CHCl}_{3}: \mathrm{MeOH}$ (97:3) of this material gave three fractions: the first was a mixture of ursolic acid and oleanolic acid methyl esters $(300 \mathrm{mg})$, the second was the methyl ester of ursolic acid $(800 \mathrm{mg})$, and the third was the methyl ester of epi-betulinic acid $(30 \mathrm{mg})$.
The crude ethanol/water (6:4) extract (48 g) was partitioned into ethyl acetate and then into n-butanol. The soluble part of $n$-Butanol (2.5 g) was submitted to column chromatography on silica gel, and eluted with $\mathrm{CHCl}_{3}$ with increasing amounts of $\mathrm{MeOH}$. After analysis by TLC some fractions were combined. Further preparative TLC eluted with $\mathrm{CHCl}_{3}: \mathrm{MeOH}(85: 15)$ of the less polar fractions gave a mixture $(5 \mathrm{mg})$ of the isomeric iridoids -gardiol and $\beta$-gardiol. Another fraction of that column was submitted to reversed-phase HPLC [column C-8 $(25 \times 0.4 \mathrm{~cm})$ and elution with a $\mathrm{H}_{2} \mathrm{O}-\mathrm{MeOH}$ gradient, at a flow rate of $8 \mathrm{~mL} / \mathrm{min}$, and detector UV (240 nm)], affording the iridoids gardenoside (17 $\mathrm{mg}$ ) and deacetylasperulosidic acid methyl ester (4 mg).

The soluble part of ethyl acetate $(200 \mathrm{mg})$ was precipitated with $\mathrm{CHCl}_{3}$. The precipitate was dissolved in $\mathrm{MeOH}$ and submitted to column chromatography on Sephadex LH-20, and eluted with MeOH. After TLC, some fractions were combined and one of them was identified as quercetin-3-O-rutinoside $(50 \mathrm{mg})$. Another fraction was submitted to preparative TLC, and eluted with $\mathrm{CHCl}_{3}: \mathrm{MeOH}: n$-BuOH: $\mathrm{H}_{2} \mathrm{O}(25: 5: 10: 1)$ to afford $12 \mathrm{mg}$ of quercetin-3-O- $\beta$-D-(2"-trans- $p$-coumaroyl)-rutinoside (1) and $25 \mathrm{mg}$ of kaempferol-3-O- $\beta$-D-(2"-trans- $p$ coumaroyl)-rutinoside (2).

\section{Acknowledgements}

The authors are grateful to $\mathrm{CNPq}$ for financial support and schalarships.

\section{References}

1. Bolzani, V. da S.; Trevisan, L.M.V.; Young, M.C.M. Phytochemistry 1991, 30, 2089.

2. Brochini, C.B.; Martins, D.; Roque, N.F.; Bolzani, V. da S. Phytochemistry 1994, 36, 1293.

3. Robbrecht, E. In Tropical Woody Rubiaceae; Vol. 1, Opera Botanica, Belgium, 1991.

4. Ty, Ph. D.; Lischewski, M.; Phiet, H.V.; Preiss, A.; Sung, T.V.; Schmidt, J.; Adam, G. Phytochemistry 1984, 23, 2889.

5. Boros, C.A.; Stermitz, F.R. J. Nat. Prod. 1990, 53, 1055.

6. Chaudhuri, R.K.; Afifi-Yazar, F.V.; Sticher, O. Helv. Chim. Acta. 1979, 62, 1603.

7. Chaudhuri, R.K.; Afifi-Yazar, F.V.; Sticher, O.; Winkler, T. Tetrahedron 1980, 36, 2317.

8. Markham, K.R.; Chari, V.M.; Mabry, T.J. In Carbon-13 NMR Spectroscopy of Flavonoids in the Flavoids: Advances in Research; Harborne, J.; Mabry, T.J., Eds.; Chapman and Hall; London, 1982, pp. 19-134.

9. Breitmaier, E.; Voelter, W. In Carbon-13 NMR Spectroscopy; UCH, 3rd Ed.; Weinheim, 1987, p. 134.

10. Agrawal, P.K.; Bansal, M.C. "Flavonoids Glycosides" In Carbon-13 NMR of Flavonoids; Agrawal, P.K., Ed.; Elsevier, Amsterdam, 1989, pp. 283-364. 